\title{
Resource allocations and disapproval voting in unequal groups
}

Citation for published version (APA):

d'Exelle, B., \& Riedl, A. M. (2013). Resource allocations and disapproval voting in unequal groups. Journal of Conflict Resolution, 57(4), 627-652. https://doi.org/10.1177/0022002712448912

Document status and date:

Published: 01/01/2013

DOI:

$10.1177 / 0022002712448912$

Document Version:

Publisher's PDF, also known as Version of record

Document license:

Taverne

Please check the document version of this publication:

- A submitted manuscript is the version of the article upon submission and before peer-review. There can be important differences between the submitted version and the official published version of record.

People interested in the research are advised to contact the author for the final version of the publication, or visit the DOI to the publisher's website.

- The final author version and the galley proof are versions of the publication after peer review.

- The final published version features the final layout of the paper including the volume, issue and page numbers.

Link to publication

\footnotetext{
General rights rights.

- You may freely distribute the URL identifying the publication in the public portal. please follow below link for the End User Agreement:

www.umlib.nl/taverne-license

Take down policy

If you believe that this document breaches copyright please contact us at:

repository@maastrichtuniversity.nl

providing details and we will investigate your claim.
}

Copyright and moral rights for the publications made accessible in the public portal are retained by the authors and/or other copyright owners and it is a condition of accessing publications that users recognise and abide by the legal requirements associated with these

- Users may download and print one copy of any publication from the public portal for the purpose of private study or research.

- You may not further distribute the material or use it for any profit-making activity or commercial gain

If the publication is distributed under the terms of Article $25 \mathrm{fa}$ of the Dutch Copyright Act, indicated by the "Taverne" license above, 
Resource Allocations and Disapproval Voting in Unequal Groups

(c) The Author(s) 2012

Reprints and permission: sagepub.com/journalsPermissions.nav DOI: $10.1177 / 00220027 / 24489 / 2$ jcr.sagepub.com @SAGE

\title{
Ben D'Exelle' and Arno RiedI ${ }^{2,3}$
}

\begin{abstract}
Resources are often allocated in groups through decentralized nonmarket mechanisms. We experimentally investigate groups where a rich representative allocates resources among poorer members, who can announce disapproval by voting for a measure hurting the representative. We examine the effect of inequality aversion by keeping information on the allocation private in one and commonly known in another condition. Further, we investigate whether casting votes publicly or secretly influences allocation and voting behavior. We find that disapproval rates are highest with secret voting or a commonly known resource allocation. Disapproval voting fails to stimulate representatives to appear more prosocial, but rather induces them to keep everything. Private information on the allocation and public voting leads to least disapproval and exclusion of the poorest group members from the resources. The analysis shows that inequality aversion of poorer group members crucially interacts with the investigated institutional and informational details of the resource allocation situation.
\end{abstract}

\section{Keywords}

allocation, disapproval voting, punishment, inequality aversion, information, exclusion, unequal groups

\footnotetext{
'School of International Development, University of East Anglia, Norwich, United Kingdom

${ }^{2}$ CESifo, Poschingerstr, Munich, Germany

${ }^{3}$ Department of Economics, School of Business and Economics, Maastricht University, Maastricht, Netherlands
}

\section{Corresponding Author:}

Arno Riedl, Department of Economics, School of Business and Economics, Maastricht University, P.O. Box 616, 6200 MD, Maastricht, Netherlands.

Email: a.riedI@maastrichtuniversity.nl 


\section{Introduction}

Markets and government transfers are undoubtedly important allocation mechanisms of scarce resources. However, in many instances, these mechanisms are not available or suitable and money, goods, or services are allocated in other, decentralized ways. The allocation of budgets between departments at universities, firms, or governmental bodies and the allocation of resources in organizations and alliances like the United Nations and the European Union are macro examples at hand.

At a more micro scale, people all over the world participate in clubs, voluntary groups, and other organizations where resources are allocated in a decentralized nonmarket fashion (Knack and Keefer 1997). In addition, for many African countries that are constrained by both weak governance structures and underdeveloped markets, the allocation of resources through decentralized nonmarket channels has a promising potential to find a way out of poverty and stimulate economic growth (Hayami and Godo 2005). In fact, development aid is increasingly distributed through representatives of local groups and communities. According to conservative calculations, the World Bank's portfolio allocated in this way has increased from \$325 million in 1996 to \$2 billion in 2003 (Mansuri and Rao 2004). Yet, several studies point out that a main difficulty of such community-driven development lies in the vulnerability to capture by local elites (Alderman 2001; Conning and Kevane 2002; Platteau and Gaspart 2003; Ravallion 2003; D’Exelle 2009).

In this article, we experimentally study if and how the decentralized allocation of resources in unequal groups is affected by the interaction of inequality aversion and different information conditions regarding the allocation of resources and disapproval voting. Although our setup reflects the basic features of many of the decentralized resource allocation situations mentioned above, for concreteness, in the following we frame it as an extended version of the so-called leader-disciplining mechanism (LDM). This mechanism was first introduced by Platteau and Gaspart (2003) as a theoretically effective means to deter elite capture in communitydriven development. The LDM describes a strategic situation between an aid donor and a local relatively rich leader representing a village who allocates resources provided by the aid donor among himself and the poorer villagers. The main feature of the LDM is that the aid donor does not provide resources at once but in two tranches, where the second tranche is paid out to the representative only after the villagers approved the representatives division of resources and, hence, is thought to serve as a disciplining device for the representative.

In our version of the LDM, the disciplining device is the strongest, hence, most effective, possible as it is factually equivalent to asking the representative to allocate the promised resources out of his own pocket first, with the guarantee of full reimbursement in case the villagers approve the allocation, but no reimbursement in case the villagers disapprove it. Specifically, in our experiment, we investigate resource allocations in groups consisting of a permanent representative and three other group members (villagers) who differ in their initial wealth. The rich representative 
repeatedly allocates resources among the poorer villagers, who have (also repeatedly) the possibility to announce their approval or disapproval of the resource allocation by voting for or against it.

Besides the allocation behavior of representatives and voting behavior of villagers in general, we are also interested in how these behaviors are affected by important institutional and informational details of the resource allocation situation. Furthermore, since by now there is ample evidence that people care not only about their own material well-being but are averse toward inequality (for surveys see, e.g., Camerer 2003; Cooper and Kagel 2010), we also investigate if and how these details interact with inequality aversion.

First, to gain insights into the interaction between inequality aversion in unequal groups and disapproval voting, we vary the information on the allocation decision of the rich representative by keeping it private in one condition but making it common information in another condition. If inequality aversion is a relevant behavioral motive, it should manifest itself in differences in voting behavior across information conditions, which in turn may differentially affect the representative's distribution decisions. Importantly, at the outset, it is unclear whether inequality aversion works in favor or against enhancing efficiency and equality (see, e.g., the stream of experimental studies on trust and gift-exchange games starting with Berg, Dickhaut, and McCabe [1995] and Fehr, Kirchsteiger, and Riedl [1993] that show that inequality aversion can have a positive effect, and, e.g., van Damme and Güth [1998] and Okada and Riedl [2005] who find that it can be detrimental). Therefore, from an organizational and policy design perspective, it is interesting and important to gain better knowledge of the interaction between inequality aversion and institutional details.

Second, we examine whether and how casting votes publicly or secretly influences allocation decisions and voting behavior. Although secret voting is surely a widely used way of casting votes, casual evidence suggests that public voting is popular, too; especially in smaller groups that interact repeatedly. It strikes us to be of importance for policy design to investigate how these different modes of balloting affect the allocation of resources and disapproval voting, especially in repeated interactions and with actors of unequal wealth. In our experiment, we impose secret voting in one condition and public voting in another. Importantly, in a repeated interaction setting as the one we investigate, a representative may benefit from public voting in that she or he can identify those who approved and those who disapproved the resource allocation. The representative may use this information and in response reallocate resources in the future accordingly. The anticipation and experience of such strategically guided resource allocations may in turn induce different voting behaviors in secret and public voting.

We use a laboratory experiment to analyze the effects of information on allocation and voting behavior because it allows us to fully control the variables of interest. In the field, it is impossible to observe behavior when voting is secret and when it is public, in otherwise identical situations. The same holds true for the variation of information regarding the actually allocated resources. Field empirical data usually 
allow observing behavior either when allocations are publicly known or when they are private knowledge. To causally investigate the effect of information disclosure, the controlled environment of the laboratory is very helpful.

In our analysis, we specifically focus on the following issues: (1) the determinants of disapproval voting behavior of villagers, (2) the allocation decision strategies of representatives, and (3) the response of representatives to disapproval of an allocation. For all three issues, we examine in detail how the observed behaviors interact with information on resource allocation and the two voting procedures.

Our main results are briefly summarized here. First, observed behavior contradicts predictions based on the standard assumption of common knowledge of rationality and narrow selfishness but is consistent with the assumption that (at least some) of the participants are inequality averse. Second, villagers are more likely to disapprove when voting is secret or information on the allocation is common, which leads to higher disapproval rates in these conditions. Third, villagers' voting behavior is strongly influenced by the share they receive and the poorest villager has the highest likelihood to cast a disapproval vote. Fourth, we identify different strategies of representatives and find that disapproval of an allocation has a detrimental effect on representatives' subsequent prosocial behavior. Specifically, once disapproved, representatives switch to a strategy where they allocate nothing to the villagers and have a strong tendency to stick to this strategy. Finally, disapproval rates vary considerably across the different information conditions, which explains differences in representatives' strategies across treatments. In particular, representatives least often allocate nothing to the villagers when voting is public, and completely exclude exactly one of the villagers from the resources most often when the resource allocation is not disclosed. Moreover, it is the poorest villager who is most often excluded by the representative. In summary, our results indicate that the behavior of villagers is clearly driven by inequality aversion and interacts with the investigated institutional designs, which in turn affects the resource allocations of representatives.

Our study is related to several streams of experimental research. The literature on the effect of decentralized punishment in public good games and common pool settings (pioneered by Fehr and Gächter [2000] and Ostrom, Walker, and Gardner [1992], respectively) has shown that group members are ready to punish free riders even at a cost to themselves. While related, our study differs in various aspects from this literature. First, we do not investigate a social dilemma but a pure resource allocation problem. Second, in our study "punishment" (i.e., disapproval) is not an individual act but coordinated through the political instrument of voting. Third, we analyze a situation where actors differ in their initial wealth level, which is not the case in most of the social dilemma with punishment studies (for recent exceptions, see Reuben and Riedl 2009, 2011). Studies extending the ultimatum game to multiple responders (Knez and Camerer 1995; Güth, Schmidt, and Sutter 2004; Riedl and Vyrastekova 2004) are also related. The main difference with these studies is that in our experiment the rejection of an unfair resource allocation cannot be imposed unilaterally but is organized via majority voting. In addition, as in the social dilemma 
experiments, in these multiple responder ultimatum game experiments responders do not differ in their initial wealth levels.

That disclosure of resource allocations may influence both proposers' and responders' behavior has been demonstrated for bilateral bargaining settings (Croson 1996). However, so far the only study having looked at the importance of information disclosure in settings with multiple responders is van Damme and Güth (1998). Our study also adds to this literature by comparing different information treatments regarding resource allocation and voting. Finally, our study is related to the experimental political science literature on committee decision making that emerged mainly in the 70 s and 80 s of the last century (for a survey, see McKelvey and Ordeshook 1990) and the more recent investigations into legislative bargaining (see, e.g., Fréchette, Kagel, and Lehrer 2003; Kagel, Sung, and Winter 2010). Our research differs from that literature, as these studies are interested in coalitional bargaining outcomes and the behavior of committees and legislative bodies, while we investigate a bargaining mechanism with one representative and add sanctioning via the political instrument of voting.

The rest of the article is organized as follows: the next section presents the experimental design and procedures, followed by theoretical considerations and the presentation of research hypotheses. Thereafter, we present the empirical results. In the last section, we summarize the experiment and present some conclusions.

\section{Experimental Design and Procedures}

The experiment groups consisting of one "representative" and three "villagers" are engaged in a repeated game, where the representative allocates resources among the group members, after which the villagers can vote for approval or disapproval of the allocation. ${ }^{1}$ At the beginning of a round, group members receive an initial endowment that can be thought of as their initial wealth. Since we are interested in allocation behavior in unequal groups, these endowments differ across group members, inducing initial wealth inequality. It is reasonable to assume that the representative is the richest person (see Platteau and Gaspart 2003; Mansuri and Rao 2004, among others), an assumption also often made in more general political economy models (see, e.g., Besley and Coate 1997). Therefore, in the experiment, the representative, $R$, receives the largest endowment $E_{R}=200$ francs. The poorer villagers also differ in their initial wealth. There are two "middle-endowment villagers," $M 1$ and $M 2$, each receiving an endowment $E_{M 1}=E_{M 2}=150$ francs, and one "low-endowment" villager $L$, the poorest group member, who receives $E_{L}=100$ francs. $^{2}$ The allocation game is played for ten consecutive rounds in the same group. Each round consists of the following two stages:

Stage 1: At the beginning of the stage, the representative $R$ allocates an additional amount of resources $I=200$ francs, which can be thought of as the resources 
potentially provided by an aid donor, among all group members. Importantly, the leader-disciplining mechanism (LDM) of the aid donor stipulates that the allocation has to be paid out of the pocket of the representative first and is reimbursed by the aid donor only in case the villagers approve the allocation. At the end of the stage, villagers are informed about their shares.

Stage 2: Villagers $M 1, M 2$, and $L$ simultaneously and independently vote in favor or against approval of the allocation. Thereafter, all members are informed whether the proposed allocation is approved or not and, hence, whether the representative is reimbursed or not, and individual earnings are calculated.

In stage 2 , an allocation is disapproved by simple majority voting. The monetary payoffs of the group members are determined in the following way. In principle, the income of each member increases according to the representative's allocation of 200 francs. However, if two or three villagers vote in favor of disapproval, the representative's payoff is in fact reduced by an amount $K=200$ francs, because in that case he is not reimbursed by the aid donor. In addition, each villager's earnings are reduced by an amount $k=20$ francs, which may be interpreted as transaction costs of disapproval voting. ${ }^{3}$ If less than two villagers vote in favor of disapproval, no costs are inflicted on any of the members.

We have chosen the amount of resources potentially provided by the aid donor such that the representative can in principle equalize earnings for all members. Furthermore, compared to experiments that allow for costly punishment, in our case disapproval has a high impact to cost ratio and hits the representative in absolute terms relatively severely. We have deliberately chosen these parameter values because disapproval voting needs coordination among villagers, which may make this mechanism behaviorally less effective than individual punishment as implemented in public goods games (see, e.g., Fehr and Gächter 2000; Egas and Riedl 2008).

Next to the general allocation behavior of the representative and the voting behavior of the villagers, we are interested in how these behaviors interact with important informational and institutional details. One such detail is the information villagers have regarding the representative's allocation. This is particularly interesting because experimental evidence shows that people do care about earnings inequalities (see, e.g., Camerer 2003; Cooper and Kagel 2010). In consequence, in our setup, differences in information on the representative's allocation may influence villagers' voting decisions, as different information conditions allow for different social comparison processes. In turn, if the representative is anticipating such behavioral effects, actual allocation decisions may also depend on the available information regarding the allocation. To investigate this, we implement two conditions that differ in the information villagers have on the representative's allocation. Specifically, we compare a situation with Common Information on the allocation of the resources (CI, for short) with a situation where each villager has only Private Information on her individual absolute share (PI). In our example of a representative allocating aid resources among villagers, information on the allocation is likely to be 
Table I. Treatments and Number of Groups.

\begin{tabular}{lcc}
\hline & Secret voting & Public voting \\
\hline Private information on the allocation $(\mathrm{Pl})$ & 8 & 8 \\
Common information on the allocation $(\mathrm{Cl})$ & 7 & 8 \\
\hline
\end{tabular}

relevant. It is easily conceivable that potential protest against unequal aid distributions (including "elite capture") can be more easily avoided when the representative manages to keep private how the total amount of aid resources is distributed.

In addition, we are interested whether and, if yes, how two prominent ways of casting votes affect allocation and voting behavior. First, secret voting, which is the general principle in most democratic general elections, and, second, public voting that is often implemented in decision making in smaller groups, such as committees and other important decision bodies (e.g., the grand jury). Together with the information conditions regarding the representative's allocation this leads to the $2 \times 2$ factorial design depicted in Table 1. The table also shows the number of groups in each treatment, which are our independent units of observation.

The experiment was completely computerized using the Z-tree software (Fischbacher 2007) and conducted in the computer lab of Maastricht University. In total, 124 students participated in thirty-one groups; 52.4 percent of the participants were male and the average age was 21.8 with a minimum of 18 and a maximum of 31 . Each subject participated in exactly one treatment and none had participated in a similar experiment before. Each session lasted between 90 and 120 minutes and average earnings were 22.20 euros, which varied between 10.70 euros and 31.70 euros. Detailed experimental procedures and the instructions can be found in the Supplementary Material (SM, Resource Allocations and Disapproval Voting in Unequal Groups).

\section{Theoretical Considerations and Hypotheses}

In this section, we develop our main behavioral hypotheses. We start with a discussion of probable strategies of villagers in the voting subgame, and how these could be influenced by inequality aversion and the implemented information conditions. Thereafter, we look at the strategy choices of the representative. Our hypotheses are partly based on theoretical considerations and partly derived from behavioral regularities observed in other experiments. For convenience, we present the theoretical arguments informally and delegate their formal description and derivations to the SM.

As any decision situation involving a majority voting rule, our game is plagued with the existence of a plethora of Nash (1950) equilibria (see, e.g., the theoretical and experimental literature on legislative bargaining; Baron and Ferejohn 1989; Fréchette et al. 2003). In fact, it can be shown (Proposition 1 in the SM) that any allocation decision by the representative can be supported as a subgame perfect Nash equilibrium (SPNE; Selten 1965). However, most of these equilibria have the 
unappealing feature that they involve the use of weakly dominated strategies. Therefore, we focus on SPNE that only involve undominated strategies (USPNE for short). In our game, such equilibria are characterized by the attractive feature that a villager votes in favor of disapproving an allocation if and only if she receives a higher utility in case the allocation is actually disapproved than when it is approved. In the SM, we show that in our game such an equilibrium always exists and is unique (Lemma 1).

\section{Villagers' Voting Decisions}

Whether a villager votes in favor of disapproval may depend on the representative's allocation decision, the villager's preferences and-because of the majority ruleon the number of other villagers voting in favor of disapproval. With the standard assumption of common knowledge of rationality and narrow material self-interest, the fact that voting is costly makes all villagers prefer that the representative's allocation is not disapproved, irrespective of the actual allocation. In consequence, the unique uSPNE predicts that we should observe representatives giving nothing (or very little) to the villagers who will accept, because they cannot expect more in case the allocation is disapproved (Proposition 2 in the SM).

However, there is extensive experimental evidence suggesting that this is not a realistic outcome. For instance, in take-it-or-leave-it ultimatum games, it is regularly observed that responders reject positive but unfair offers in favor of lower but more equal outcomes (Güth, Schmittberger, and Schwarze 1982; for an overview see Camerer 2003). To accommodate this and other behavioral regularities, models incorporating concerns for fairness through "inequality aversion," have been developed (Fehr and Schmidt 1999; Bolton and Ockenfels 2000; Charness and Rabin 2002).

In our resource allocation situation, these models imply that if villagers are sufficiently averse to inequality and distribution proposals are sufficiently unequal, villagers may in utility terms be better off when the representative's proposal is disapproved and the representative, thus, not reimbursed by the aid donor. In that case, the overall income of the representative is reduced more than the villagers' income, which reduces inequality between the representative and the villagers. Specifically, we show in the SM that, if villagers are inequality averse, there are indeed allocation decisions where villagers vote in favor of disapproval (Lemmas 2 and 3, Propositions 3 and 4 in the SM). An important insight from our theoretical analysis is that, in order to vote for approving an allocation, the poorest villagers need to be offered the highest shares. This implies that, for any given allocation proposal, the likelihood that the poorest villager votes in favor of disapproval is higher than that a middle-endowment villager will do so. ${ }^{4}$

Intuitively, the likelihood of disapproval voting depends on the representative's actual allocation. Indeed, for any given intensity of inequality aversion there exists a threshold of the received share below which a villager will prefer disapproval, and hence will vote in favor of it, while when her share is above it she will vote against 
disapproval (Lemmas 2 and 3, Propositions 3 and 4 in the SM). Consequently, we can theoretically predict that the likelihood of voting in favor of disapproval decreases with the share proposed to a villager. We are now ready to formulate our first set of hypotheses regarding villagers' behavior:

Hypothesis VIL-1: (1) Villagers' propensity to vote in favor of disapproval decreases with the share they are offered. (2) The poorest villagers show a higher propensity to vote in favor of disapproval than the middle-endowment villagers.

Up to now, we have discussed that when villagers are inequality averse they may prefer disapproval of an allocation over approving it, irrespective of whether the whole allocation or only their own share is disclosed to them. In the following paragraph we discuss possible effects of the investigated information conditions on the propensity to vote in favor of disapproval. It seems intuitive that voting behavior will depend on whether a villager knows the whole allocation or only her own share. In the latter case, villagers can compare their own income only to the income of the other three members as a whole, whereas in the former case comparisons can be made with respect to each individual other group member. In particular, when the whole allocation is disclosed, villagers can compare the share proposed to them with the share the representative keeps for himself.

In the SM (Lemmas 2 and 3), we show that these differences in information disclosure imply different threshold levels regarding the own shares at which villagers switch from preferring disapproval of the allocation to approval of it. Using this result, we show that the possibility to compare one's share directly with what the representative keeps (as in the CI condition), instead of only with the whole group (as in the PI condition), can make villagers more reluctant to accept an unfair share (Proposition 5). ${ }^{5}$ We therefore hypothesize that villagers are more willing to vote in favor of disapproval when there is common knowledge of the distributional consequences of the representative's allocation. Accordingly, we formulate the following hypothesis:

Hypothesis VIL-2: Villagers are more likely to vote in favor of disapproval when there is common information of the allocation than when they only know their own share.

From a theoretical point of view, it is inessential whether voting is secret or public. However, behaviorally it may make a difference especially when we take the repeated nature of the game into account. When voting is secret individual villagers' voting behavior is never disclosed, whereas when voting is public each villager's vote is known to all, including the representative. The information disclosure in the latter case may make villagers reluctant to vote in favor of disapproval because they may fear retaliation of the representative. In particular, given that only two villagers need to be convinced to avoid disapproval, representatives may use information on the voting decisions to exclude those villagers who are more difficult to satisfy. In 
turn, villagers may take this into account when deciding on which vote to cast. This leads us to the following hypothesis:

Hypothesis VIL-3: Villagers are more likely to vote in favor of disapproval of the allocation when voting is secret than when voting is public.

The arguments leading to hypotheses VIL-2 and VIL-3 immediately imply different expected disapproval rates, which we formulate as our next hypothesis.

Hypothesis VIL-4: Disapproval rates are higher when there is common information on the representative's allocation decision than when this information is private. Disapproval is also more frequent when voting is secret than when it is public.

\section{Representative's Allocation Behavior}

Representatives who are strongly averse against advantageous inequality will make proposals that equalize overall income, while representatives who are not strongly advantageous inequality averse will behave like representatives who are pure money maximizers. ${ }^{6}$ In the following we derive results for the latter. Recall that the LDM inherent in our setup is thought to prevent the representative from capturing all or most of the resources provided by the aid donor. We have seen already that under the assumption of standard selfish preferences, the mechanism cannot prevent such elite capture because villagers will never disapprove, irrespective of the share of resources they are offered. Using the hypotheses on villagers' behavior, we now discuss whether villagers' inequality aversion will make the mechanism theoretically more effective and how it interacts with the investigated information and voting conditions. We have seen previously that with inequality averse villagers disapproval becomes a likely outcome when allocations are sufficiently unfair. Hence, the representative needs to consider how his allocation decision may influence the likelihood of disapproval voting. For example, because disapproval is implemented by majority voting a representative could try to build a "minimal coalition," where he satisfies only two villagers and excludes the third one by offering her nothing (which we will call an "exclude-one" strategy). If successful, a representative using such a strategy could avoid disapproval while keeping a relatively high share of the resources. Indeed, it can be theoretically shown that if villagers are sufficiently inequality averse such a strategy could be optimal for representatives (Propositions 3 and 4 in the SM). In principle, this holds for both the PI and the CI conditions.

Importantly, however, villagers' inequality aversion is not known to the representative and likely varies across villagers. Therefore, if the offered shares to the villagers are too low or if they are very inequality averse an "exclude-one" strategy might be unsuccessful in avoiding disapproval. In that case, representatives are actually better off by choosing an "exclude-all" strategy where their proposal is also likely to be disapproved but they end up with a higher overall share of the resources. 
Which of these strategies is actually preferred by a representative depends on the likelihood of disapproval associated with each strategy. Given the hypothesized effects of allocation disclosure and voting rules on villagers' voting behavior (VIL-2 and VIL-3) and, hence, the likelihood of disapproval, the frequency of the discussed strategies will likely differ across the investigated conditions in the way described in the following hypothesis:

Hypothesis REP-1: Representatives less often use an exclude-one strategy (and more often the exclude-all strategy) (1) when there is common information on the allocation than when each villager only knows her own share and (2) when voting is secret than when it is public.

In the SM, it is shown that the poorest villager needs to be offered the largest share in order to prefer the approval outcome (Lemmas 2 and 3). Intuitively, this is the case because she has the worst starting position and, hence, needs most compensation to get on par with the other villagers and not to fall too far behind the representative in terms of final income. Therefore, for a representative who applies the exclude-one strategy, it is optimal to exclude the poorest villager (Propositions 3 and 4 in the SM) (Abbink and Ellman 2010).

Hypothesis REP-2: Representatives who implement the exclude-one strategy will most likely exclude the poorest villager.

The preceding discussion deals with aggregate outcomes but is silent about the possible dynamics leading to these outcomes. For a fully informed representative, it can be optimal to form a minimal coalition with two middle-endowment villagers. However, as already pointed out, representatives have only incomplete information about villagers' inequality aversion. Hence, especially in early rounds they might - by mistake - choose allocations where two or more villagers still vote in favor of disapproval. Representatives experiencing disapproval, although offering positive shares to the villagers, may find it optimal to revert to the secure "exclude-all" strategy. Importantly, in comparison to an unsuccessful other strategy, keeping all resources will not lower the likelihood of disapproval and representatives applying such a strategy will not learn more about the villagers' true inequality aversion. In turn, this may make them stick to this secure strategy. We formulate our first hypothesis regarding the dynamics of representatives' strategy choices:

Hypothesis REP-3: Experienced disapproval induces representatives to switch to the exclude-all strategy, and once using this strategy they are likely to stick to it.

In Hypothesis REP-1, we formulated our expectations regarding representative's strategy choices in the different treatments. Here we formulate some ideas about the dynamics leading to these outcomes. According to Hypothesis VIL-4, disapproval rates are higher when the allocation is commonly known (CI condition) or voting 
is secret than when each villager only knows her own share (PI condition) or voting is public. This, together with the fact that the representative has only incomplete knowledge about the villagers' inequality aversion, implies that a representative will find it more difficult to avoid disapproval (and hence more likely switch to the exclude-all strategy) in the CI condition or when voting is secret than in the PI condition or when voting is public. This leads us to our second hypothesis regarding representatives' adjustment of strategies:

Hypothesis REP-4: In the treatments where allocation decisions are commonly known or voting is secret, representatives will most frequently switch to the exclude-all strategy.

Overall, we have seen that theoretically the LDM can lead to disapproval voting due to inequality aversion among villagers. The developed hypotheses also predict that both voting behavior and representatives' allocations depend on whether the allocation is commonly known or not and whether voting is public or secret. Whether these predictions are borne out by the data is discussed in the next section.

\section{Empirical Results}

We start with an analysis of voting behavior of the villagers and how it differs across treatments. Thereafter, we continue with reporting results regarding the strategies chosen by representatives. We base the statistical tests and regressions on data from all rounds. To test the robustness of the results with respect to a last round effect, we additionally perform all tests and regressions without observations from the last round. All reported results appear robust. The detailed results of the robustness test can be found in the SM.

\section{Villagers' Voting Behavior}

We use probit regression analysis to examine determinants of villagers' voting decisions (Hypotheses VIL-1 and VIL-2) and how these decisions vary across treatments (Hypotheses VIL-3 and VIL-4). Descriptive statistics of villagers' voting behavior can be found in the SM. For the regression, we pool all treatments and use a dependent variable equal to 1 if a villager voted for disapproval and zero otherwise. To investigate whether villagers are more likely to vote in favor of disapproval the lower their share (part 1 of VIL-1) and whether the poorest villagers have a higher likelihood to vote in favor of disapproval (part 2 of VIL-1), we control for the share a villager received and a dummy for the initial endowment (equal to 1 if the villager has intermediate initial wealth). We expect a higher likelihood of disapproval voting when there is common information on the allocation (CI) than when there is not (PI) (Hypothesis VIL-2). To test this, we include a dummy variable equal to 1 for the CI condition. Finally, to test the hypothesis that voting in favor of disapproval is more 
Table 2. Determinants of Disapproval Voting.

\begin{tabular}{lc}
\hline Received share & $-0.01 \mathrm{I}^{* * * *}$ \\
Middle-endowment villager (dummy) & $(0.001)$ \\
& $-0.143^{* * * *}$ \\
Common information on the allocation (dummy) & $(0.05 \mathrm{I})$ \\
& $0.118^{*}$ \\
Public voting (dummy) & $(0.064)$ \\
& $-0.129^{* *}$ \\
Pseudo $R^{2}$ & $(0.064)$ \\
Wald $\chi^{2}$ & 0.2203 \\
Prob $>\chi^{2}$ & 210.13 \\
Predicted probability & 0.0000 \\
\hline
\end{tabular}

Note. Probit regression with round fixed effects. Marginal probabilities reported. Robust standard errors to correct for intragroup dependencies.

Significance levels (two-sided): *10 percent, **5 percent, ***I percent.

likely when voting is public than when it is secret (Hypothesis VIL-3) we include a dummy variable equal to 1 for the public voting condition.

Table 2 reports the results of the probit regression. As expected, the received share exerts a significantly negative influence on villagers' likelihood to vote in favor of disapproval. We also find that, in line with our hypothesis, middleendowment villagers have a significantly lower probability of voting for disapproval (14.3 percent) than the poorest villagers.

The regression table also shows that in CI, where the allocation is fully disclosed to all villagers, the villagers' propensity to vote in favor of disapproval increases significantly ( $p<.10$ for two-sided test). In addition, as hypothesized, we find a significant adverse effect of public voting on disapproval voting. With public voting, villagers are 12.9 percent less likely to vote for disapproval. Hence, Hypotheses VIL-2 and VIL-3 find support by the data. We summarize the main observations in a first result.

Result 1. Determinants of villagers' voting decisions: Villagers' propensity of disapproval voting significantly decreases with the received share and is highest for the poorest villagers. In addition, villagers are more likely to vote in favor of disapproval when the allocation of resources is common information and when voting is secret.

So far, we have looked at individual voting decisions. However, it is actually implemented disapproval that affects final earnings and potentially influences the representative's decisions. Therefore, we take a closer look at the disapproval rate and how it differs across treatments. In the following, we take the disapproval rate in each group across all rounds as the independent unit of observation. We find that the 
disapproval rates are significantly lower in the public voting and PI treatment (median rate: 0.30 ) than in the secret voting and CI treatment (median rate: 0.60 ) (Mann-Whitney (MW) $z=2.767$; one-sided $p=.003$ ). For all other pair-wise treatment comparisons, differences are not statistically significant $(p>.218$, two-sided MW tests). When pooling the data of PI and CI, disapproval of the allocation is significantly more frequent when voting is secret (median rate: 0.50 ) than when it is public (median rate: 0.30$)(\mathrm{MW} z=1.734$; one-sided $p=.042$ ). When pooling the data of both voting conditions, disapproval is more frequent in CI (median rate: 0.60 ) than in PI (median rate: 0.30 ; $\mathrm{MW} z=1.495$; one-sided $p=.068$ ). These observations are summarized in the following result, which is in concordance with Hypothesis VIL-4.

Result 2. Disapproval rates across treatments: Disapproval rates are lower (1) when villagers are informed only about their own share than when the allocation is fully disclosed and (2) when voting is public than when it is secret.

In terms of our example, the results regarding disapproval voting support the idea that inequality aversion could make the LDM effective, because inequality averse villagers are more likely to disapprove an allocation of resources the higher the share captured by the representative. The results also show that disapproval voting is influenced by the informational details regarding the allocation and the voting rules. Whether the LDM is actually effective naturally depends on the response of the representative to the threat and actual experience of disapproval under the different conditions. This is examined next.

\section{Representatives' Distribution Decisions}

We focus on some main results related to our hypotheses and relegate detailed descriptive statistics of the proposed distributions to the SM. To test our hypotheses regarding the strategies used by representatives, we classify them in the following way. First, we look at the number of villagers excluded by representatives. Second, we look at the share a representative keeps and distinguish between allocations where the representative keeps more than the equal share (i.e., more than 50 francs) and allocations where he keeps at most the equal share (i.e., exactly 50 francs or less). For convenience, we refer to the former as high share and to the latter as low share.

This procedure returns eight classes of strategies, which are shown in Table 3, together with their observed relative frequencies. From the table, it can be clearly seen that representatives neither exclude exactly two villagers nor do they (almost never) choose a strategy where exactly one villager is excluded and only a low share kept. In the following, without loss of substantial information, we focus on the remaining four most frequent classes of strategies, which are highlighted in Table 3.

Representatives use the exclude-one-high-share (henceforth, exclude-one) strategy, where exactly one villager is offered nothing, most frequently (32.90 percent of 
Table 3. Classification of Representatives' Strategies and Their Frequencies.

\begin{tabular}{llcc}
\hline & \multicolumn{3}{c}{ Share of representative } \\
\cline { 3 - 4 } & & Low share $(\leq 50$ francs $)(\%)$ & High share $(>50$ francs $)(\%)$ \\
\hline Excluded villagers & 3 & - & 17.74 \\
& 2 & 0.00 & 0.65 \\
& 1 & 2.90 & 32.90 \\
& 0 & 26.13 & 19.68 \\
\hline
\end{tabular}

Note. $N=$ 1240. Pooled over all rounds, groups, and treatments.

all cases). The use of this strategy is consistent with the idea that a representative tries to form a minimal coalition with two villagers who approve the allocation while keeping a relatively large share of the additional resources for himself. The excludeall strategy, where the representative keeps all additional resources, is applied in 17.74 percent of the cases. The remaining two strategies no-exclusion-low-share and no-exclusion-high-share have in common that they do not exclude any villager but differ in the share the representative keeps. The strategy no-exclusion-low-share, where the representative keeps at most the equal share, is used in 26.13 percent and the no-exclusion-high-share, where the representative keeps at least the equal share, is used in 19.68 percent of all cases.

In sum, both no-exclusion strategies comprise about 45 percent of all strategy choices. When assuming that representatives have perfect knowledge of villagers' inequality aversion, the use of these strategies is not predicted for representatives that are selfish or only weakly inequality averse. Strongly inequality-averse representatives should equalize final incomes, a strategy that is observed in only 3.23 percent of all cases. Alternatively, fair-minded but self-serving representatives may interpret equality as an equal distribution of the additional resources, which is observed in 12.80 percent of the cases. The remaining 29.78 percent of cases where no villager is excluded are likely reflecting a mixture of selfserving fair-mindedness and incomplete information about villagers' actual inequality aversion. In these cases, representatives neither exclude some villagers nor propose large shares to them.

In the remainder of this section, we focus on the strategies where either one or all villagers are excluded and test the corresponding hypotheses formulated in the previous section. Recall that we have confirmed Hypothesis VIL-4, according to which disapproval is more frequent when the representative's allocation is commonly known (CI), than when it is not (PI), and also more frequent with secret voting than with public voting (cf. Result 2). Therefore, according to Hypothesis REP-1, we should see that the exclude-one strategy is used less often (and the exclude-all strategy more often) with CI on the allocation than with PI, and when voting is secret than when it is public. To investigate this, we compare for each treatment the relative 

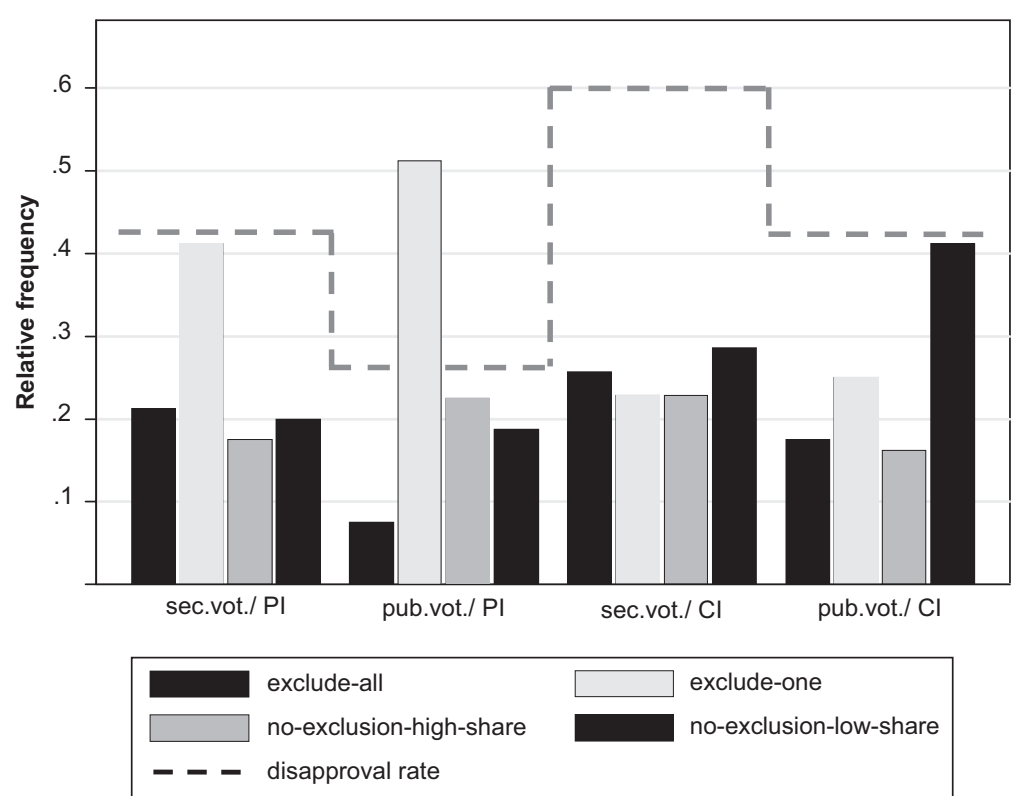

Figure I. Strategy choice and disapproval rate by treatment. Note: All rounds and groups pooled.

frequencies of the chosen strategies. Figure 1 shows these frequencies (bars) together with the disapproval rate (dashed line). There are pronounced differences in the relative frequencies of strategies used by representatives across treatments. Irrespective of the voting procedure, the exclude-one strategy is used most often when each villager only knows her own share in the allocation (PI). The noexclusion-low-share is most often used when the allocation is commonly known (CI) and voting public, whereas the frequency of the exclude-all strategy is lowest with PI and public voting.

We test whether these differences across treatments are statistically significant with pair-wise MW tests, using relative frequencies per group (i.e., representative) as independent units of observation. The exclude-one strategy is significantly more frequent in the treatment with public voting and PI (median relative frequency: 0.55 ) than in the treatment with secret voting and $\mathrm{CI}$ (median relative frequency: 0.00 ) ( $\mathrm{MW} z=1.880$; one-sided $p=.030$ ) or with public voting and CI (median relative frequency: $0.15 ; \mathrm{MW} z=1.852$; one-sided $p=.032$ ). All other pair-wise treatment comparisons do not show statistically significant differences ( $p$ values $>.186$, two-sided tests).

The significant differences are mainly driven by the difference in used strategies in PI and CI. Pooling the data for both voting rules and comparing PI and CI shows 
that the exclude-one strategy is used significantly less often when the allocation is commonly known (CI) (median relative frequency: 0.10 ) than when each villager only knows her own share (PI) (median relative frequency: 0.50) ( $\mathrm{MW} z=1.733$; one-sided $p=.042$ ). This result supports the first part of Hypothesis REP-1 regarding differences in the use of that strategy in PI and CI. The second part of Hypothesis REP-1 predicts also a differential use of that strategy under the two voting rules. However, no significant difference is found when pooling the data of PI and CI and comparing secret voting (median relative frequency: 0.20$)$ and public voting (median relative frequency: 0.30) ( $\mathrm{MW} z=1.128$; one-sided $p=.130$ ).

The exclude-all strategy is significantly used less often when voting is public and each villager only knows his or her own share (PI) (median relative frequency: 0.05) than in the treatments with secret voting and common information on the allocation (CI) (median relative frequency: 0.20) ( $\mathrm{MW} z=1.808$; one-sided $p=.036)$ and secret voting and private information $(\mathrm{PI})$ (median relative frequency: 0.15) (MW $z=1.480$; one-sided $p=.069$ ).

At closer inspection, the significant differences can be attributed to differences in behavior in the two voting conditions. When pooling the data of PI and CI, the relative frequency of the exclude-all strategy is significantly lower with public voting (median relative frequency: 0.05$)$ than with secret voting (median relative frequency: 0.20) (MW $z=1.757$; one-sided $p=.040$ ). This result supports the second part of Hypothesis REP-1, regarding differences in the use of the exclude-all strategy under the two voting rules. For the first part of Hypothesis REP-1, which predicts different frequencies of the exclude-all strategy when the information on the allocation differs, no statistical support is found. (PI: median relative frequency: 0.10; CI: median relative frequency: $0.10 ; \mathrm{MW} z=0.654$; one-sided $p=.257$ ). All remaining pairwise treatment comparisons for this strategy also do not reveal significant differences ( $p>.314$, two-sided MW tests). Finally, the relative frequencies of the no-exclusion-low-share-strategy and the no-exclusion-high-share-strategy do not significantly differ across treatments $(p>.205$ and $p>.237$, respectively, twosided MW tests). We summarize the significant test results in the following result:

Result 3. Representatives' use of exclude-one and exclude-all strategies: The exclude-one strategy is used most often when villagers know only their own share in the allocation (PI) and the exclude-all strategy is used least often when voting is public.

Hypothesis REP-2 predicts that the poorest villagers are the ones who are most likely excluded when representatives use the exclude-one strategy. To test this, we take observations where the exclude-one strategy is followed and estimate with a probit regression the likelihood that a villager with a particular initial wealth is excluded. For this, we use a dummy variable that is equal to 1 if the villager is the poorest one (otherwise 0 ) as explanatory variable. We estimate separate regressions for the public and secret voting treatments, which allows us to test whether excluding the poorest villager 
Table 4. Likelihood of Excluded Villager.

\begin{tabular}{lccccc}
\hline & \multicolumn{2}{c}{ Secret voting } & & \multicolumn{2}{c}{ Public voting } \\
\cline { 2 - 3 } \cline { 5 - 6 } & Marg. Prob. & SE & & Marg. Prob. & SE \\
\hline Poorest villager (dummy) & -0.072 & 0.251 & & $0.400^{* * *}$ & 0.154 \\
$N$ & 126 & & & 180 & \\
Pseudo $R^{2}$ & .0041 & & & .1236 & \\
Observed probability & .3333 & & & .3333 & \\
\hline
\end{tabular}

Note. Probit regression with round fixed effects. Robust standard errors (SE) to correct for intragroup dependencies. Only observations with "exclude-one" strategy.

Significance levels (two-sided): *10 percent, **5 percent, ***। percent.

follows from a correct anticipation of poorest villagers' higher propensity to disapproval voting, or if it is the result of representatives observing and learning that. The latter is only possible when voting is public. Table 4 presents the results.

With secret voting, the estimated coefficient is insignificant. With public voting, however, poorest villagers have a 40 percent higher probability to be excluded. Hence, we can confirm Hypothesis REP-2 when voting is public. Recall that from our regression results on villagers' voting behavior we know that poorest villagers have a higher propensity of disapproval voting. Since this is observed by representatives only when voting is public, the result is consistent with the interpretation that representatives have (a) incomplete knowledge of villagers' inequality aversion and, thus, their inclination to vote in favor of disapproval and (b) that they respond to the observed higher likelihood of disapproval voting of the poorest villagers by excluding them. We summarize this in the following result:

Result 4. Representatives' use of the exclude-one strategy: Representatives who follow the exclude-one strategy most likely exclude the poorest villager, when voting is public.

Regarding our guiding example, the previous two results together with the observed frequencies of strategy use lends partial support to the effectiveness of the LDM. On the positive side, we observe that representatives are far from trying to capture all additional resources most of the time. Yet, on the negative side, we observe the following: first, there are still many cases where representatives capture all the resources (17.74 percent of the allocation decisions; Table 3); second, in many cases, strategies excluding at least one villager are used (54.19 percent of the allocation decisions; Table 3); third, when exactly one villager is excluded it mostly hits the poorest one. In the following, we present results that shed some light on the reasons for the latter observations.

In particular, we analyze dynamics in the adjustment process of representatives' strategies over time and how this relates to experienced disapproval. Recall that 
Table 5. Likelihood of the "Exclude-All" Strategy.

\begin{tabular}{lcc}
\hline & Coef. & $S E$ \\
\hline Disapproval in round $t-$ I (dummy) & $1.909 * * *$ & 0.354 \\
Exclude-all-strategy in round $t-$ I (dummy) & $2.048^{* * *}$ & 0.694 \\
Disapproval with exclude-all-strategy in round $t-$ I (dummy) & $-1.924^{* * *}$ & 0.732 \\
Constant & $-2.284^{* * *}$ & 0.323 \\
$N$ & 279 & \\
Wald $\chi^{2}$ & 39.18 & \\
Prob $>\chi^{2}$ & .0000 & \\
\hline
\end{tabular}

Note. Random effects panel data model. The start of the process coincides with the start of the observation period for each individual, therefore the initial observations can be assumed to be exogenous and a standard random effects probit model estimated (Stewart 2006).

Significance levels (two-sided): * 10 percent, **5 percent, ***I percent.

Hypothesis REP-3 states that experienced disapproval leads to a more frequent use of the exclude-all strategy and that there is some inertia once it is used. To test this, we run the following probit regression. The dependent variable takes the value 1 if the representative chooses the exclude-all strategy and 0 otherwise. Three dummy variables are added as explanatory variables. The first dummy is equal to 1 when the representative experienced disapproval in the previous round; the second dummy is equal to 1 when the representative chose the exclude-all strategy in the previous round; the third dummy is equal to 1 when the representative chose the exclude-all strategy and also experienced disapproval in the previous round. Table 5 shows the results.

All three coefficients are statistically significant. The significantly positive coefficient of the dummy indicating experienced disapproval in the previous round shows that representatives who were not using the exclude-all strategy (in this case, the other two dummies are equal to zero) have a significantly higher likelihood of changing their strategy into the exclude-all strategy after having experienced disapproval. We also observe that the coefficient of the second dummy, indicating the use of the exclude-all strategy in the previous round, is significantly positive, whereas the coefficients of the other two dummies nullify each other (they are similar in size but of opposite sign). This shows that irrespective of having experienced disapproval or approval in the previous round, once the exclude-all strategy is used, representatives tend to stick to this strategy. We summarize this in the following result

Result 5. Disapproval and the use of the exclude-all strategy: Experienced disapproval induces representatives to switch to the exclude-all strategy and once using this strategy representatives are very likely to stick to it.

We have seen that disapproval rates as well as representatives' strategy choices differ across treatments (Results 2 and 3). We now investigate whether there are 
Table 6. Correlation of Strategy Choice and Disapproval with Rounds.

\begin{tabular}{lccccr}
\hline & \multicolumn{4}{c}{ Strategies } & \\
\cline { 2 - 5 } Treatments & Exclude-all & Exclude-one & $\begin{array}{c}\text { No-exclusion } \\
\text { high-share }\end{array}$ & $\begin{array}{c}\text { No-exclusion } \\
\text { low-share }\end{array}$ & $\begin{array}{c}\text { Disapproval } \\
\text { rate }\end{array}$ \\
\hline $\mathrm{Pl} /$ sec.vot. & $0.818^{* * * *}$ & $-0.619 *$ & -0.532 & $0.652 * *$ & 0.485 \\
$\mathrm{Pl} /$ pub.vot. & -0.275 & 0.359 & 0.117 & -0.125 & -0.304 \\
$\mathrm{Cl} /$ sec.vot. & $0.749 * *$ & 0.342 & $-0.619 *$ & 0.178 & -0.045 \\
Cl/pub.vot. & $0.776^{* * *}$ & 0.389 & $-0.820^{* * *}$ & 0.392 & 0.161 \\
\hline
\end{tabular}

Note. Spearman rank-order correlation coefficients; significance levels (two-sided): *10 percent, **5 percent, ***I percent.

different dynamics in the strategy choice, across treatments, or if representatives settle on their strategies right from the beginning. We also take a closer look at the dynamics of disapproval in the different treatments.

Table 6 shows for each treatment the Spearman correlation coefficient between the relative frequency of a particular strategy in a certain round and the round number. In the last column, the table also shows the Spearman correlation coefficient between disapproval rates and the round number. The correlations reported in the table clearly show that in all except one treatment the frequency of the exclude-all strategy strongly and significantly increases over time at the expense of other strategies. Only in the treatment with public voting and private information on the allocation (PI), strategy choices do not significantly change over time.

Table 6 also shows that over time the exclude-all strategy is used more often at the expense of the exclude-one strategy when villagers only know their own share (PI) and voting is secret, while representatives stick to the exclude-one strategy with PI and when voting is public. In the latter treatment, the use of the exclude-one strategy is also relatively successful in avoiding disapproval as in this treatment the exclude-one strategy is most frequent and disapproval rates are lowest (cf. Figure 1). Interestingly, in no treatment, disapproval rates significantly increase over time. This confirms that in the three treatments where we see an increased use of the exclude-all strategy, it is experienced disapproval that makes representatives to switch to this strategy. We formulate our final result which is largely confirming our Hypothesis REP-4.

Result 6. Disapproval and the dynamics of different strategies: With secret voting or common information on the allocation representatives have a tendency to switch to the exclude-all strategy. In the treatment where villagers only know their own share of the allocation and voting is public, disapproval is relatively infrequent and many representatives follow the exclude-one strategy without exhibiting a significant trend to change strategies. 
Regarding our example, these results suggest that the inability of a LDM to completely ban elite capture and exclusion is partly induced by the fact that representatives are unable to avoid disapproval voting of inequality averse villagers. In response, representatives either stick to a strategy where exactly one villager is excluded, which induces relatively low disapproval rates, or revert to the "safe" strategy of excluding all villagers from the aid resources.

\section{Conclusion}

In this article, we experimentally study resource allocations among groups with members who differ in their initial wealth and where a permanent representative repeatedly distributes resources among poorer members. To examine the effectiveness of a political control instrument of majority disapproval voting which materially hurts the representative, we systematically vary information regarding resource allocations and examine the effects of secret and public disapproval voting.

We find that disapproval is not very effective in enforcing representatives to behave more prosocially. Quite to the contrary, disapproval increases the frequency with which representatives keep all resources leaving nothing to the rest of the group. Importantly, however, disapproval voting and representatives' resource allocations are systematically influenced by information regarding the actual allocation and the voting regime. First, we find that disapproval rates are highest when voting is secret or when the allocation is commonly known. Second, representatives are relatively successful in avoiding disapproval by excluding the poorest group member from the resources, when information on received shares is private and voting is public. These results are a consequence of voting behavior: the probability of voting in favor of disapproval decreases with the received share of resources and the poorest group members have a significantly higher propensity to vote in favor of disapproval.

For concreteness, in the article, we have put our setup into the frame of the allocation of resources provided by an aid donor through a local representative and interpreted the possibility of disapproval as an LDM. Hence, our results can be interpreted as a laboratory test of this specific LDM, which turned out to be only partially successful. On the positive side, we observe that representatives do not always try to capture all resources because inequality averse villagers are likely to disapprove such an unfair allocation. On the negative side, we still observe quite some instances where representatives try to appropriate all resources, mainly because they fail to avoid disapproval. Furthermore, representatives try to build a minimal coalition where they exclude the poorest villager.

Beyond the concrete example, our study sheds light on the role of information regarding resource allocations and disapproval voting in more general settings akin to our setup and described in the Introduction. Specifically, private versus common information on the allocation and secret versus public voting have systematic and significant differential effects on intended and actual disapproval as well as the ultimately emerging distribution of wealth. When group members only know their own 
share of the allocation and voting is public, disapproval rates are substantially lower and thus efficiency is higher. At the same time, however, under these conditions the poorest member of the group is mostly excluded from all resources. Hence, for optimal policy design, our results suggest that policy makers should take information effects and voting rules into account but will need to choose between the lesser of two evils: inefficiency and inequality.

Notably, the observed exclude-one strategy in our game resembles the minimal winning coalition equilibrium as predicted in legislative bargaining games with closed rule (Baron and Ferejohn 1989). In our experiment, the representative aims to satisfy a "minimal majority" by giving two of the three other group members a sufficiently high share to make them approving the allocation. Similarly, in legislative bargaining with closed rule, only a minimal majority of committee members receives a positive share of the distributed benefits. However, while the emergence of a minimal majority voting equilibrium in legislative bargaining does not require inequality averse agents, the exclude-one equilibrium in our game requires such "social preferences" on the voters' side. In our game, the "reversion level" (the payoff without agreement) of a voter increases with a higher share received because, in contrast to legislative bargaining games, the allocation is always implemented, irrespective of the voting outcome. With selfish preferences this implies that no voter has any incentive to disapprove an allocation as her reversion level is always lower than what she would get without disapproval. Yet, when introducing inequality aversion, for sufficiently unfair proposals, the reversion level may be larger than the utility from just accepting the proposal. This also points at the importance of taking into account the potential interaction between inequality aversion and details of the decision environment when analyzing decentralized allocation mechanisms.

There are a couple of extensions that seem interesting to be pursued in future work. First, the material loss for the representative due to disapproval is rather high and the cost-to-effectiveness ratio for the potentially disapproving voters rather low. Nevertheless, we find that representatives do not behave strongly prosocial. Evidence from related public goods with punishment experiments suggest that a smaller material loss would be even less effective in inducing prosocial behavior (see Egas and Riedl [2008] Nikiforakis and Normann [2008], and the discussion in the Introduction). Yet, our setup of resource allocation with disapproval voting differs in several aspects from public goods with individual punishment experiments, which may make it worthwhile to investigate the robustness of our results in respect to the costto-effectiveness ratio of disapproval. Second, the situation investigated in our experiment applies to groups and organizations where a single representative remains firmly in power. Admittedly, the assumption of a permanent representative is not applicable in all decentralized resource allocation problems and altering it may lead to interesting new insights. Specifically, voting behavior and distribution decisions may change when a threat of replacement by alternative representatives exists. Third, resource allocations are not always imposed in a dictatorial way, but are often the outcome of a more complicated bargaining process. Therefore, future research 
should allow for more complex bargaining procedures, perhaps with differences in bargaining power between group members. Fourth, in our experiment, the different institutions were imposed exogenously and kept fixed within each treatment. However, in the field communities and groups, often design institutions themselves that may change over time. Therefore, endogenous institution formation is another interesting avenue of future research. A recent study that takes the endogeneity of institutions seriously is Kosfeld, Okada, and Riedl (2009), who studied the conditions under which sanctioning institutions are formed in public good experiments. It would be interesting to extend such research to resource allocation problems as discussed in this article.

\section{Acknowledgments}

The authors are grateful to participants of the Behavioral and Experimental Economics group meetings of Maastricht University who helped us to improve the experimental design and Martin Strobel for his advice on Z-tree programming.

\section{Authors' Note}

This article is part of the research project "Experimental analysis of the formation, dynamics, and economic consequences of social networks" financed by the Oesterreichische National bank (project number 11429). The research documented in this work also benefited from the financial support of the Institute of Development Policy and Management (University of Antwerp). The data and Stata do-file used to generate the results as well as other supporting materials are available at JCR's website.

\section{Declaration of Conflicting Interests}

The authors declared no potential conflicts of interest with respect to the research, authorship, and/or publication of this article.

\section{Funding}

The authors received no financial support for the research, authorship, and/or publication of this article, other than stated in the Authors' Note.

\section{Notes}

1. In the experiment subjects in a group were labeled A, B, C, and D, and also otherwise neutral labels were used (see the experiment instructions in the SM).

2. We use francs as the experimental money unit. Participants were paid their total earnings according to the exchange rate of 100 francs $=50$ euro cent.

3. There are transaction costs of disapproval because, in our leading example, a disapproval voting outcome has to be communicated to the aid donor. Since aid donors usually do not have their offices in the villages but in urban centers informing them is costly for the villagers (e.g., travelling costs, communication costs). To cover these costs, a representative of the villagers may be paid from contributions made by all villagers. We let each villager 
bear the same cost irrespective of her individual voting decision because we want to avoid complications by adding an additional collective action dimension to the voting decisions.

4. To derive this result, we assume that inequality aversion is not the same for all villagers and that subjects represent a random sample of the distribution of tastes.

5. In the SM, we show that for reasonably assumed inequity parameters it holds that a middleendowment villager is more likely to vote in favor of disapproval under common information whenever the representative keeps at least 72 francs.

6. Regarding the representative, disadvantageous inequality does not play a role because he can always make a proposal that equalizes income and such a proposal will never be disapproved. Further, a representative with Fehr-Schmidt inequality aversion and advantageous inequality parameter $\beta$ larger or equal $3 / 4$ will make a proposal that equalizes income. Intuitively, this is the case because the marginal utility increase from keeping one more unit of money is one, which is smaller (or at most equal) than the marginal utility decrease from increased advantageous inequality of $4 / 3 \times \beta$ ( $\beta$ is larger or equal than $3 / 4)$. The FehrSchmidt assumption of self-centered inequality aversion guarantees that the representative does not make a proposal that makes her worse off than in the equal income case. If $\beta$ is strictly smaller than $3 / 4$ the opposite reasoning applies. In that case, the representative's utility is strictly increasing in her own monetary payoff (despite the increase in advantageous inequality) and the optimal action is to maximize her income subject to the villagers' disapproval voting behavior. Hence, representatives who are not strongly advantageous inequality averse will behave like representatives who are pure money maximizers.

\section{References}

Abbink, Klaus, and Matthew Ellman. 2010. "The Donor Problem: An Experimental Analysis of Beneficiary Empowerment." The Journal of Development Studies 46 (8): 1327-44.

Alderman, Harold. 2001. "Do Local Officials know Something We don't? Decentralization of Targeted Transfers in Albania." Journal of Public Economics 83:375-404.

Baron, David P., and John A. Ferejohn. 1989. "Bargaining in Legislatures." The American Political Science Review 83:1181-206.

Berg, Joyce, John Dickhaut, and Kevin McCabe. 1995. "Trust, Reciprocity, and Social History." Games and Economic Behavior 10:122-42.

Besley, Timothy, and Stephen Coate. 1997. “An Economic Model of Representative Democracy." Quarterly Journal of Economics 112:85-114.

Bolton, Gary E., and Axel Ockenfels. 2000. "ERC-A Theory of Equity, Reciprocity and Competition." American Economic Review 90:166-93.

Camerer, Colin F. 2003. Behavioral Game Theory. Princeton, NJ: Princeton University Press. Charness, Gary, and Matthew Rabin. 2002. "Understanding Social Preferences with Simple Tests." Quarterly Journal of Economics 117:817-69.

Conning, Jonathan, and Michael Kevane. 2002. "Community-based Targeting Mechanisms for Social Safety Nets: A Critical Review." World Development 30:375-94.

Cooper David, J., and John H. Kagel 2010. "Other Regarding Preferences: A Selective Survey of Experimental Results." In The Handbook of Experimental Economics, vol. 2, edited by J. Kagel and A. Roth. 
Croson, Rachel T.A. 1996. "Information in Ultimatum Games: An Experimental Study." Journal of Economic Behavior \& Organization 30:197-213.

D'Exelle, Ben. 2009. "Excluded Again: Village Politics at the Aid Interface." Journal of Development Studies 45 (9): 1-18.

Egas, Martijn, and Arno Riedl. 2008. "The Economics of Altruistic Punishment and the Maintenance of Cooperation." Proceedings of the Royal Society B: Biological Sciences 275: 871-78.

Fehr, Ernst, and Simon Gächter. 2000. "Cooperation and Punishment in Public Goods Experiments." American Economic Review 90:980-94.

Fehr, Ernst, Georg Kirchsteiger, and Arno Ried1. 1993. "Does Fairness Prevent Market Clearing? An Experimental Investigation.” Quarterly Journal of Economics 108:437-59.

Fehr, Ernst, and Klaus M. Schmidt. 1999. "A Theory of Fairness, Competition and Cooperation." Quarterly Journal of Economics 114:817-68.

Fischbacher, Urs. 2007. "z-Tree: Zürich Toolbox for Ready-made Economic Experiments." Experimental Economics 10 (2): 171-78.

Fréchette, Guillaume R., John H. Kagel, and Steven F. Lehrer. 2003. "Bargaining in Legislatures: An Experimental Investigation of Open versus Closed Amendment Rules." American Political Science Review 97:221-32.

Güth, Werner, Carsten Schmidt, and Matthias Sutter. 2004. "Bargaining Outside the Lab: A Newspaper Experiment of a Three Person Ultimatum Game." The Economic Journal 117: 449-69.

Güth, Werner, Rolf Schmittberger, and Bernd Schwarze. 1982. “An Experimental Analysis of Ultimatum Bargaining." Journal of Economic Behaviour and Organization 3:367-88.

Hayami, Yujiro, and Yoshihisa Godo. 2005. Development Economics: From the Poverty to the Wealth of Nations. Oxford, UK: Oxford University Press.

Kagel, John H., Hankyoung Sung, and Eyal Winter. 2010. "Veto Power in Committees: An Experimental Study.” Experimental Economics 13:167-88.

Knack, Stephen, and Philip Keefer. 1997. "Does Social Capital have an Economic Payoff? A Cross-country Investigation." The Quarterly Journal of Economics 112:1251-88.

Knez, Marc J., and Colin F. Camerer. 1995. "Outside Options and Social Comparison in Three-player Ultimatum Game Experiments." Games and Economic Behavior 10:65-94.

Kosfeld, Michael, Akira Okada, and Arno Riedl. 2009. "Institution Formation in Public Goods Games.” American Economic Review 99:1335-55.

Mansuri, Ghazala, and Vijayendra Rao. 2004. "Community-based and-driven development: A Critical Review." The World Bank Research Observer 19:1-39.

McKelvey, Richard D., and Peter C. Ordeshook. 1990. "A Decade of Experimental Research on Spatial Models of Elections and Committees. In Readings in the Spatial Theory of Voting, edited by J. M. Enlow and M. J. Hinich, 99-144. Cambridge: Cambridge University Press.

Nash, John F. 1950. "Equilibrium Points in N-person Games." Proceedings of the National Academy of Sciences 36:48-49.

Nikiforakis, Nikos, and Hans-Theo Normann. 2008. "A Comparative Statics Analysis of Punishment in Public-good Experiments.” Experimental Economics 11:358-69. 
Okada, Akira, and Arno Riedl. 2005. "Inefficiency and Social Exclusion in a Coalition Formation Game: Experimental Evidence." Games and Economics Behavior 50:278-311.

Ostrom, Elinor, James Walker, and Roy Gardner. 1992. "Covenants with and Without a Sword: Self Governance is Possible." American Political Science Review 86:404-17.

Platteau, Jean-Philippe, and Frederic Gaspart. 2003. "The Risk of Resource Misappropriation in Community-driven Development." World Development 31:1687-703.

Ravallion, Martin. 2003. Targeted Transfers in Poor Countries: Revisiting the Trade-offs and Policy Options. World Bank Policy Research Working Paper 3048, Washington.

Reuben, Ernesto, and Arno Riedl. 2009. "Public Goods Provision and Sanctioning in Privileged Groups." Journal of Conflict Resolution 53:72-93.

Reuben, Ernesto, and Arno Ried1. 2011. "Enforcement of Contribution Norms in Public Good Games with Heterogeneous Populations.” CESifo Working Paper Series No. 2725.

Riedl, Arno, and Jana Vyrastekova. 2004. "Receiver Behavior in Three-person Ultimatum Game Experiments. Mimeo.

Selten, Reinhard. 1965. "Spieltheoretische Behandlung eines Oligopolmodels mit Nachfrageträgheit.” Zeitschrift für die gesamte Staastwissenschaft 121:301-24.

Stewart, Mark B. 2006. Redprob: A Stata Program for the Heckman Estimator of the Random Effects Dynamic Probit Model. Mimeo, University of Warwick.

van Damme, Eric, and Werner Güth. 1998. "Information, Strategic behavior, and Fairness in Ultimatum Bargaining: An Experimental Study." Journal of Mathematical Psychology 42:227-47. 